\title{
A New Method For Input Installation Impedance Measurement
}

\author{
*Imene ELFEKI, Thierry DOLIGEZ \\ LAN - Laboratoire des Applications Numériques \\ Tours, France \\ ielfeki@lanpark.eu
}

\author{
*Ismail AOUICHAK, Jean-Charles \\ LEBUNETEL, *Yves RAINGEAUD, \\ *GREMAN Laboratory - University of Tours \\ Tours, France \\ Aouichak;lebunetel; raingeaud @univ-tours.fr
}

\begin{abstract}
The access impedance for Narrowband PLC communication is dependent of the global installation impedance. The interest of this paper is to measure the domestic installation impedance using a new setup based on an LCL filter for masking the network impedance. The short-time and the frequency variation of the global impedance in the frequency band between 30 and $500 \mathrm{kHz}$ is measured in several scenarios. The domestic loads are classified according to their impact on the global installation impedance by connecting to the installation and changing the mode of operation. The access impedance is recalculated using the measured installation impedance in parallel to the network.
\end{abstract}

Keywords-installation impedance; access impedance; loads; short-time; LCL filter, classification; Narroband

\section{INTRODUCTION}

The use of powerline distribution network for data communication is an old solution that interested many energy distributors in the world. The main advantage of narrowband powerline communication PLC technologies resides in the use of existing cables infrastructure between the transformer substation and the smart meter in the customer side. The PLC outdoor transmission is characterized by a low impedance specifically in the customer side $[1,2]$.

Domestic installations in the same electrical network are physically linked to each other's so the access impedance measured in many works $[3,4,5]$ is impacted mainly by the input impedance of the customer installation and the impedance of the network. In this article, we have an interest to measure the impedance of one domestic installation.

Indoor PLC communications use the home grid as a transmission support. In France, the standard NFC 15-100 regulates the low voltage electrical installations [6]. It guarantees the protection of the installation by the using of a general circuit breaker and protection device attached to the house electrical panel. From this panel every departure has the differential circuit breaker and an electrical cable with an adapted section to supply many devices like the lighting circuits, socket, heating, water heater, etc. Each of these loads can be connected on bypass, star, cascade or a combination of all these solutions.

Many studies have an interest to simulate a scenario of a global installation impedance $[7,8]$ by the paralleling of some loads $[7,8]$ but the complexity of the architecture in the customer installation make the simulation of the total impedance of the installation very difficult. It is impossible to predict the domestic architecture and the number of loads connected. Also, the simulation need the knowledge of the impedances of each domestic load, but they vary according to the brand and the type of the equipment.

In our study, we have an interest about the measurement of different scenarios of the impedance of a domestic installation as a function of loads connected. The goal is to identify the loads which has the major impact on the global impedance of the installation. To realize this measure, a new setup is developed to mask the network impedance which is time and frequency variable using an LCL filter.

The domestics load are time and frequency variable $[9,10,11,12,13]$, that's why, we have an interest to study the short-time variation of the installation impedance and the impact of the global impedance of installation on the access impedance measured in parallel to the meter.

This paper is organized as follows: in the section II, the conception of the LCL filter is presented. In the section III, the filter installation and the global impedance measurement method are described. In the section IV, the measurement of the installation impedance is used to recalculate the access impedance. In the section $\mathrm{V}$, the classification of the domestic loads according to its impact on the global impedance measurement of the installation is introduced. In the section VI, the impact of the loads on the access impedance is studied and finally in the section VII, the short-time variation of the installation impedance will be introduced.

\section{LCL FILTER DEVELOPPEMENT}

The LCL filter is realized to mask the network impedance which is time and frequency variable $[2,3,4]$. The impedance of the filter must be high because the domestic installation impedance will be installed in parallel to the filter. The risk of measurement of the impedance of the filter can appear if its impedance is very low. The filter impedance must be also time invariant.

To respect this specification, an LCL filter is proposed with a first coil L1 equal to $3.6 \mathrm{mH}$, a capacitance equal to $5 \mu \mathrm{F}$ and a second coil L2 with a value equal to $0.5 \mathrm{mH}$. The electrical schematic of the filter is presented in the fig. 1 . 


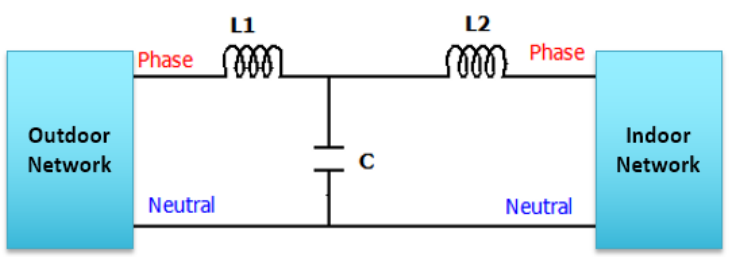

Fig. 1. Electrical schematic for of the LCL filter

The impedance of the filter is measured using a network analyzer. The impedance result is depicted in the fig. 2 .
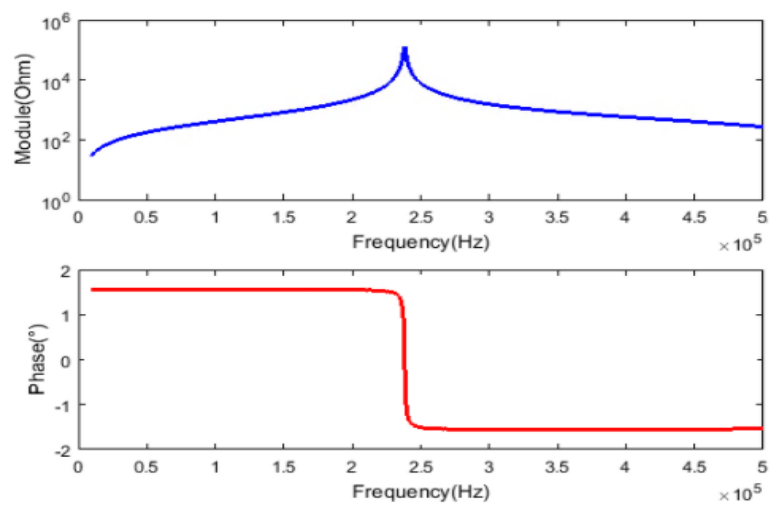

Fig. 2. Impedance of the filter

The impedance of the filter is high and varied from $90 \Omega$ in 30 $\mathrm{kHz}$ to $60 \mathrm{k} \Omega$ in the resonance peak.

\section{MEASUREMENT SETUP}

\section{A. Filter Installation}

The installation of the filter is performed on the user side in the house downstream of the meter.

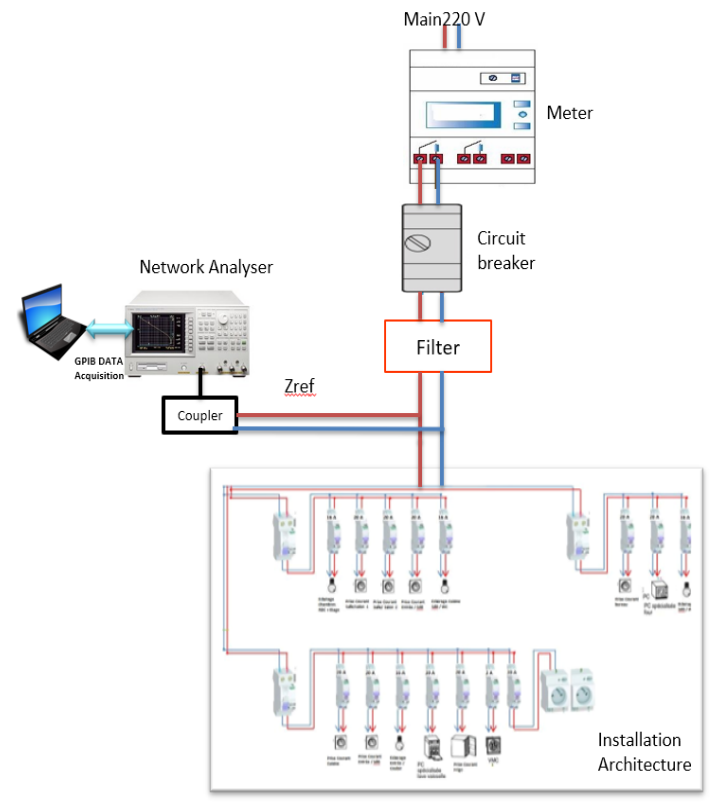

Fig. 3. Filter installation and measurement setup
The filter is set in serial between the main circuit breaker and the installation electrical panel as it presented in the fig. 3.

The measurement setup consists of the use of a capacitive coupler to filter the $50 \mathrm{~Hz}$. The network analyzer role is the measuring of the temporal and frequency variation of the impedance by the measuring of the reflection coefficient S1 1 [8]. Two types of configuration are done for the two types of measurement:

- $\quad$ For the Frequency variation.

To measure the frequency variation of the impedance, we realized a sweep with a START frequency fixed to $30 \mathrm{kHz}$ and STOP frequency equal to $500 \mathrm{kHz}$. The number of points is equal to 801 and the IFBW is set to $200 \mathrm{~Hz}$.

- For the short-time variation

To measure the impedance variation during 20 milliseconds between $30 \mathrm{kHz}$ and $500 \mathrm{kHz}$. We measured 201 points of frequency on 0 span mode. Every frequency is measured during 20 milliseconds which is the sweep time duration to measure the rapid variation of one frequency during one period of the network. Every measurement is synchronous with the frequency of the sector $50 \mathrm{~Hz}$ using a developed card for the zero crossing [14]. The results will be depicted in Time Frequency graph.

\section{B. Measurement Method}

Two measures are performed leading to the measurement of the impedance:

- Measurement of the impedance of reference Zref

This impedance of the reference represents the impedance of the network in serial with the impedance of the filter when the customer installation is disconnected to the network.

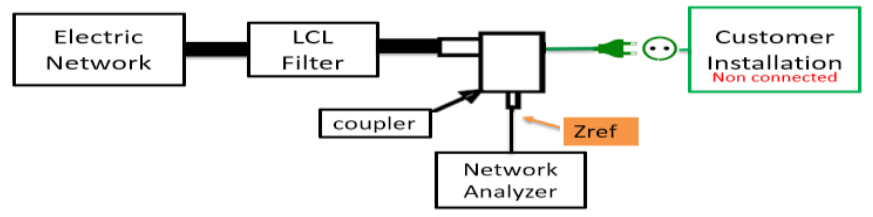

Fig. 4. Zref measurement

The measurement results of the frequency variation and shorttime variation of $Z_{\text {ref }}$ are depicted in the fig. 5 and 6.
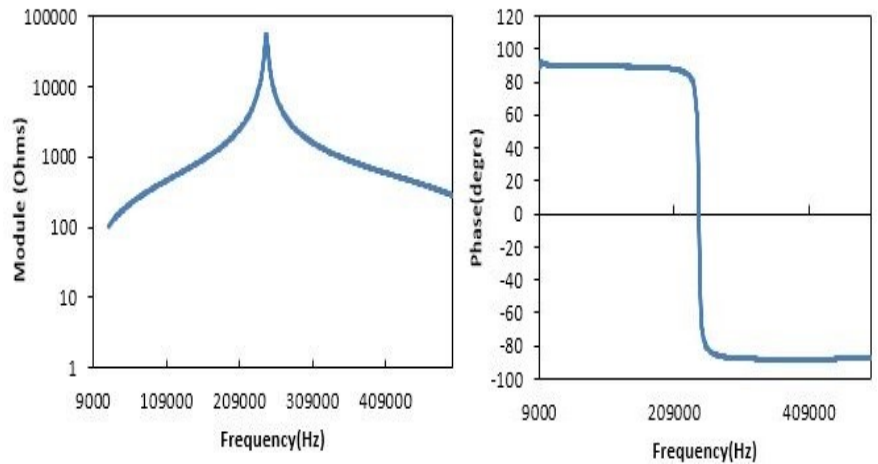

Fig. 5. Frequency variation of Zref 


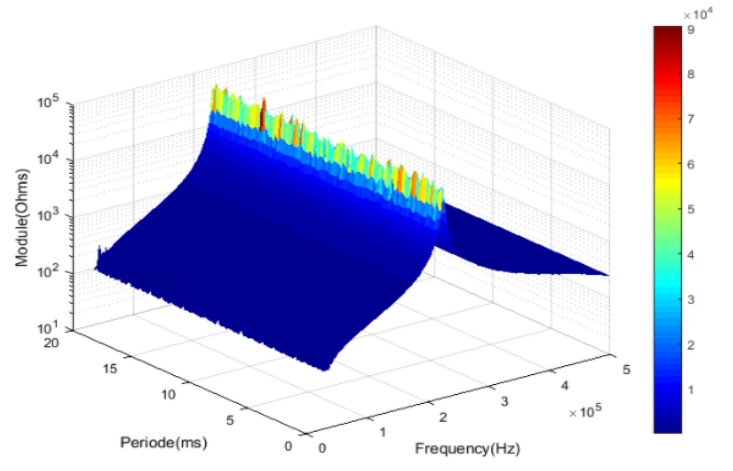

Fig. 6. Time-frequency variation of Zref

Zref has a high impedance from $100 \Omega$ to $10 \mathrm{k} \Omega$ on the resonance frequency. It represents a short time invariant behavior during the main period. This invariation masks the time variation of the impedance of the network. The reference measurement will be used to extract the input impedance of the installation $Z_{\text {installation. }}$

- Measurement of the total impedance $Z_{\text {total }}$ and deducing of $Z_{\text {installation }}$

This impedance $Z_{\text {total }}$ is equal to $Z_{\text {ref }}$ in parallel with the Zinstallation.as shown in Fig. 7.

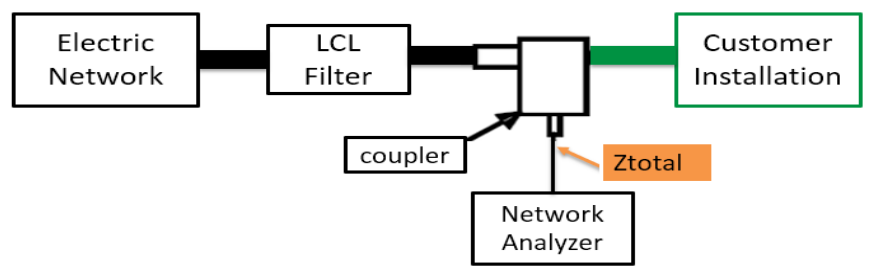

Fig. 7. Ztotal measurement

The impedance of the customer installation $Z_{\text {installation is }}$ deduced from $\mathrm{Z}_{\text {ref }}$ and $\mathrm{Z}_{\text {total }}$ according to the expression (1) and (2).

$$
\begin{aligned}
& Z_{\text {installation }}=\frac{Z_{\text {total }}^{*} Z_{\text {ref }}}{Z_{\text {ref }}-Z_{\text {total }}} \\
& Z_{\text {installation }}=\frac{Z_{\text {total }}}{1-\frac{Z_{\text {total }}}{Z_{\text {ref }}}}
\end{aligned}
$$

$Z_{\text {total }}$ is very low comparing to $Z_{\text {ref }}$ that's $\frac{Z_{\text {total }}}{Z_{\text {ref }}} \approx 0$

We conclude that $Z_{\text {total }}$ is equal to $Z$ installation, so the measured impedance would be directly Zinstallation,

\section{Input Impedance Installation Measurement Results}

The impedance of the installation is measured in the same configuration of the loads connected. The list of the connected loads consists on a laptop, a washing machine, a dryer, a printer, a lamp, a fridge, an oven, a microwave, a coffee maker tassimo, a robot, an induction table, a dishwasher, a TV, an internet box, 2 PLC plugs, a boiler, a VMC, a phone charger, an electrical couch and electric shutters.
Zinstallation. is measured in two cases:

- when the installation is connected to the network. The measurement is done using the new setup based on the filter to mask the network impedance,

- when the installation is disconnected from the electrical network the impedance is measured directly because the installation is unpowered.

The measure is done when the loads are in OFF operating mode. The results are depicted in the fig. 8 .
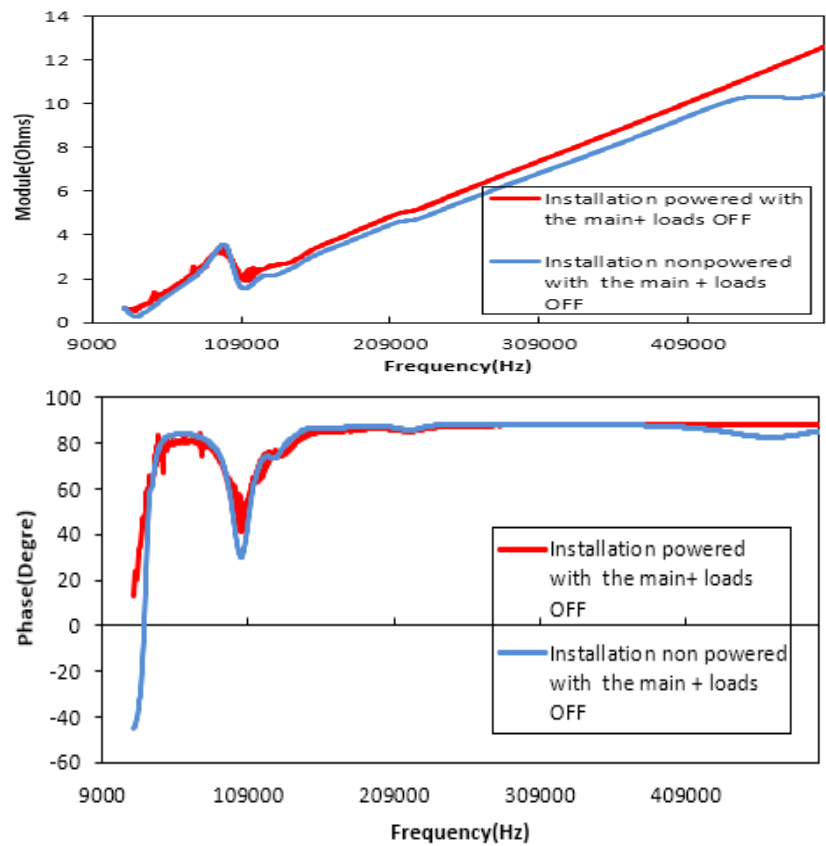

Fig. 8. The installation impedance measurement

The results show similar variation of the Zinstallation in the two cases. The impact of domestic loads connected to the installation when they are powered in OFF operating mode is very close to their impact when they are unpowered.

\section{IMPACT OF THE INSTALLATION IMPEDANCE ON THE ACCES IMPEDANCE}

The access impedance measured in the meter side represents the network impedance in parallel to the customer installation impedance.

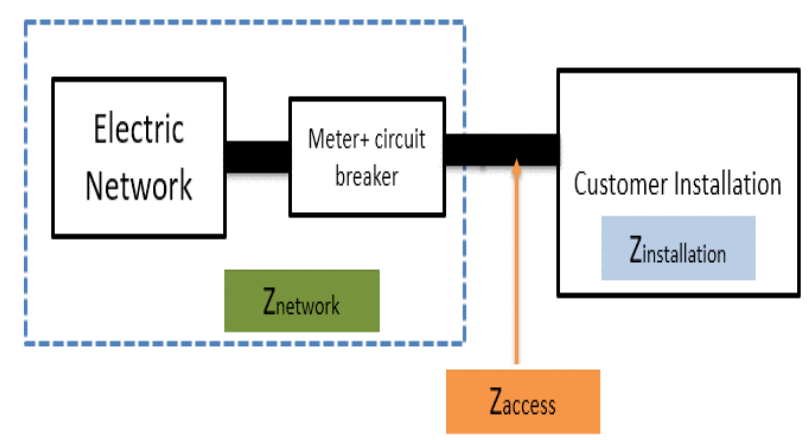

Fig. 9. Access impedance measurement point 
We measured Zinstallation and the network impedance in the meter when the installation is disconnected to the network Znetwork.
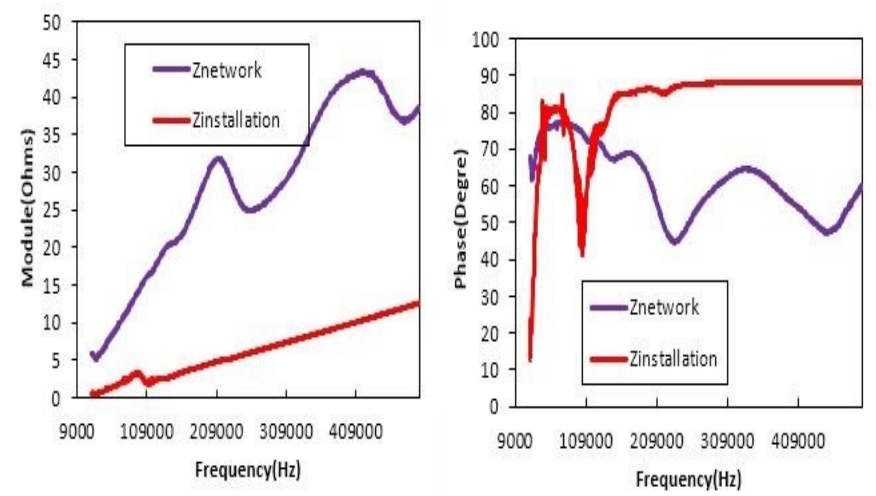

Fig. 10. Frequency variation of Znetwork and Zinstallation

The measurement results present in the Fig. 10 show the

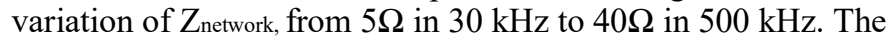
$Z$ installation is low comparing it to $Z_{\text {network. }}$ From the measurement of $Z_{\text {installation }}$ and $Z_{\text {network, we can deduce }} Z_{\text {access }}$ according to the expression (3).

$$
Z_{\text {access }}=\frac{Z_{\text {network }}{ }^{*} Z_{\text {installation }}}{Z_{\text {network }}+Z_{\text {instalalation }}}
$$

The access impedance is also measured in the meter when the customer installation is connected to the network.
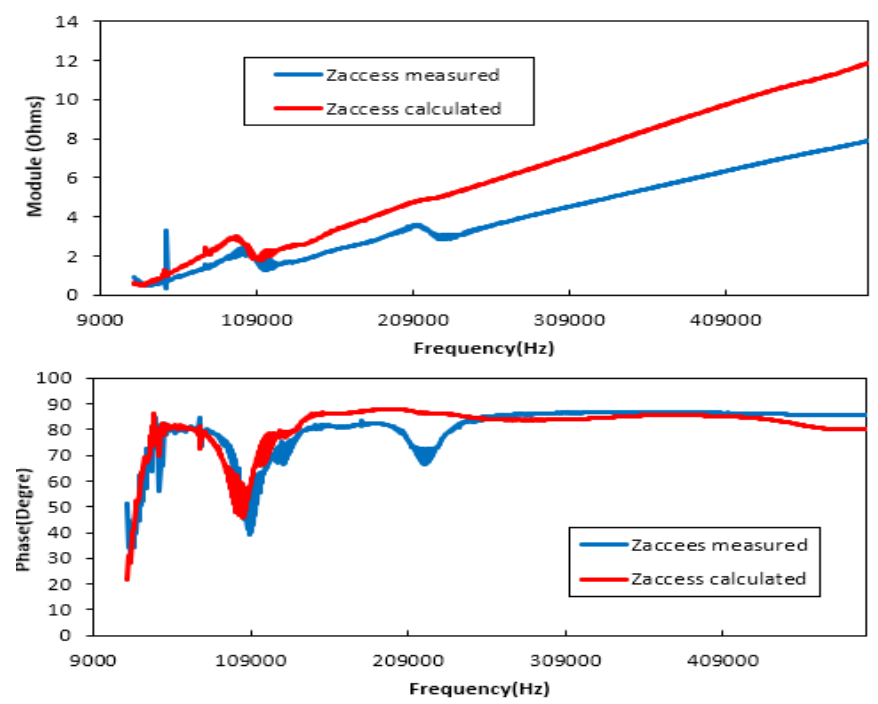

Fig. 11. Comparison of Zaccess calculated and measured

The access impedance measured and calculated has the same variation in the frequency band from $30 \mathrm{kHz}$ to $500 \mathrm{kHz}$ with a small difference $(3 \Omega$ in $500 \mathrm{kHz})$. The network and the installation impedance aren't measured in the same time. The time variation of the impedance of the network can explain the difference between the calculated and the measured measurement.

\section{IMPACT OF THE LOADS ON THE INSTALLATION IMPEDANCE}

In this part, the measurement setup is used to measure the

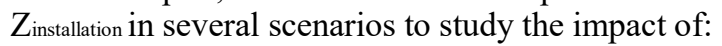

- the impedance of the electrical cable and circuit breakers,

- the loads due to their connection to the installation and the operating mode of the load (ON or OFF).

\section{A. The Impact of the Cables and The Circuit Breakers}

To measure the impedance due to those elements, we

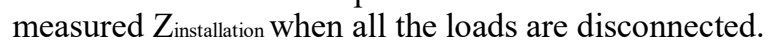
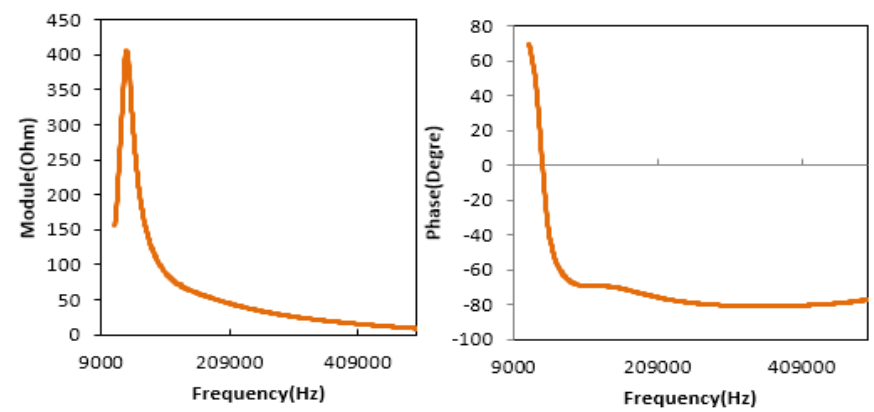

Fig. 12. Zinstallation without loads

The results presented in the fig. 12 show a high impedance in the low frequency band. The impedance decreases in function of frequency. The negative phase represents the high impact of the impedance of the cables.

\section{B. The Impact of The Loads}

To study the impact profile of some domestic loads on global impedance of the installation, $Z_{\text {installation is measured in }}$ several scenarios.

1) The impact of connecting of the loads

Zinstallation is measured for when we connected loads to the installation. The operating mode is fixed to OFF for all the loads when they are connected to the installation. Many measures show two types of loads:

- Non-impacting load
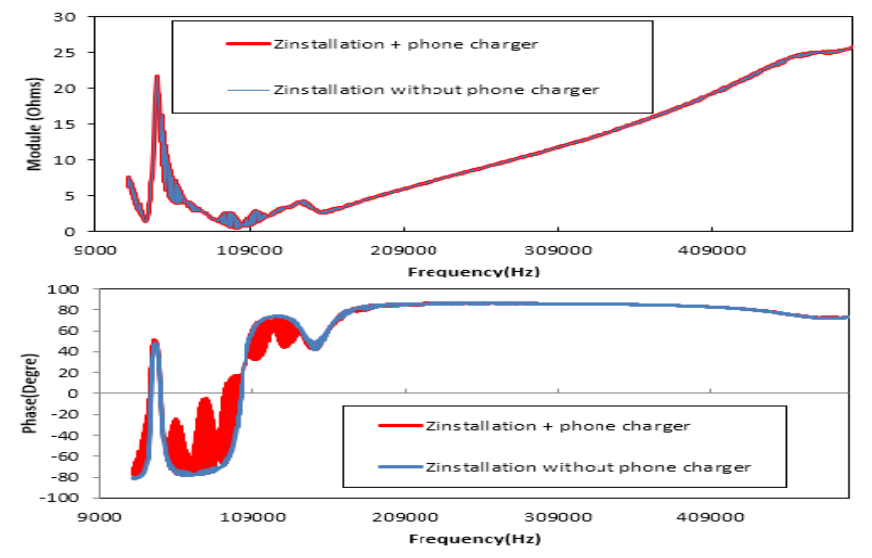

Fig. 13. Impact of the phone charger 
- Impacting loads
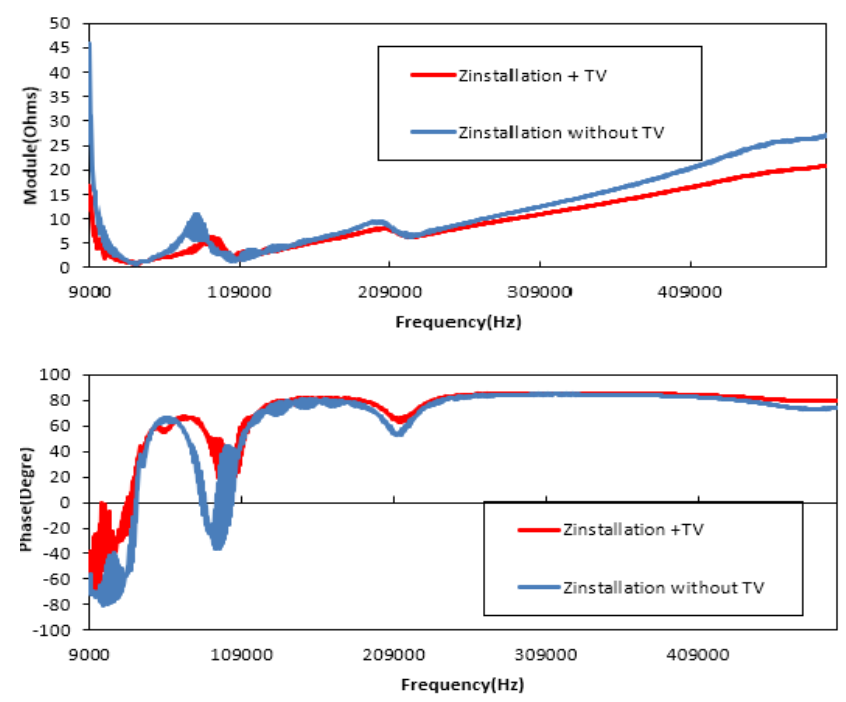

Fig. 14. Impact of the TV

We studied the impact of many domestic loads when connecting to the installation in several configurations lead to their classification in two class. Classification of the loads impact when connecting to the installation

TABLE I. ClASSIFICATION OF THE LOADS IMPACT WHEN CONNECTING TO THE INSTALLATION

\begin{tabular}{|l|c|c|}
\hline \multicolumn{3}{|c|}{ Connection of loads in OFF operating mode } \\
\hline \multicolumn{1}{|c|}{ Domestic loads } & Impacted & Non-impacted \\
\hline Waching machine & $\times$ & \\
\hline Dryer & & $\times$ \\
\hline Printer & & $\times$ \\
\hline Laptop & $\times$ & \\
\hline lamp & & $\times$ \\
\hline Oven & $\times$ & \\
\hline Microwave & $\times$ & \\
\hline Caffee maker & $\times$ & \\
\hline Robot & $\times$ & \\
\hline Electrical couch & $\times$ & \\
\hline Induction table & & $\times$ \\
\hline Boiler & $\times$ & \\
\hline Dishwasher & & $\times$ \\
\hline VMC & $\times$ & \\
\hline Fridge with open door & $\times$ & \\
\hline TV & & $\times$ \\
\hline Phone charger & \\
\hline
\end{tabular}

Many loads have a major impact on the global impedance of the installation. The impacting loads at the connection are the loads that have a low impedance in the frequency band from 30 to $500 \mathrm{kHz}$. Some loads like the washing machine and the phone charger and some type of lamp does not cause any frequency variation of the impedance, but they generate some types of noise such as the phone charger.

\section{2) Impact of the operating mode (OFF to $O N)$}

In general, the domestic loads are always connected to the installation and the user does not disconnect the equipment, but it changes their operating mode. This is why in this party we are interested to classify the loads according to their impact on the global impedance of installation when they change their operating mode from OFF mode to ON. Many measure are carried out in different scenarios shows two types of loads.
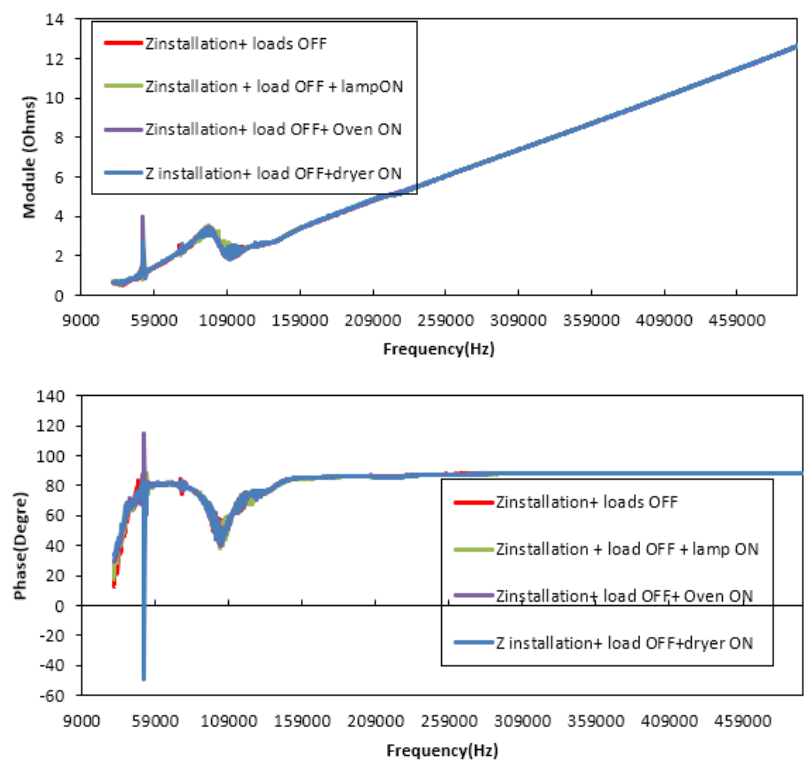

Fig. 15. Non-impact of the lamp, the oven and the dryer

We studied the impact of many domestic loads when we changed their operating mode from OFF to ON.

TABLE II. CLASSIFICATI:ON OF LOADS IMPACT ACCORFING TO THE OPERATING MODE

\begin{tabular}{|l|c|c|}
\hline \multicolumn{3}{|c|}{ Switch from OFF to ON } \\
\hline \multicolumn{1}{|c|}{ Domestic loads } & Impacted & Non-impacted \\
\hline Waching machine & & $\times$ \\
\hline Dryer & & $\times$ \\
\hline Printer & & $\times$ \\
\hline Laptop & & $\times$ \\
\hline lamp & & $\times$ \\
\hline Oven & $\times$ & $\times$ \\
\hline Microwave & $\times$ & \\
\hline Caffee maker & $\times$ & \\
\hline Robot & & $\times$ \\
\hline Electrical couch & & $\times$ \\
\hline Induction table & & $\times$ \\
\hline Boiler & & $\times$ \\
\hline Dishwasher & & $\times$ \\
\hline VMC & & $\times$ \\
\hline Fridge open / closed door & $\times$ & \\
\hline TV & & $\times$ \\
\hline Phone charger & \\
\hline
\end{tabular}

Most loads have non-impact when the operating mode pass to $\mathrm{ON}$ except for the TV, robot and the coffee marker.

\section{IMPACT OF THE LOADS ON THE ACCES IMPEDANCE}

The measurement of the access impedance when the customer installation is connected to the electrical network is carried out in several scenarios to study the impact of the connection of some loads on the access impedance measured in the meter. 

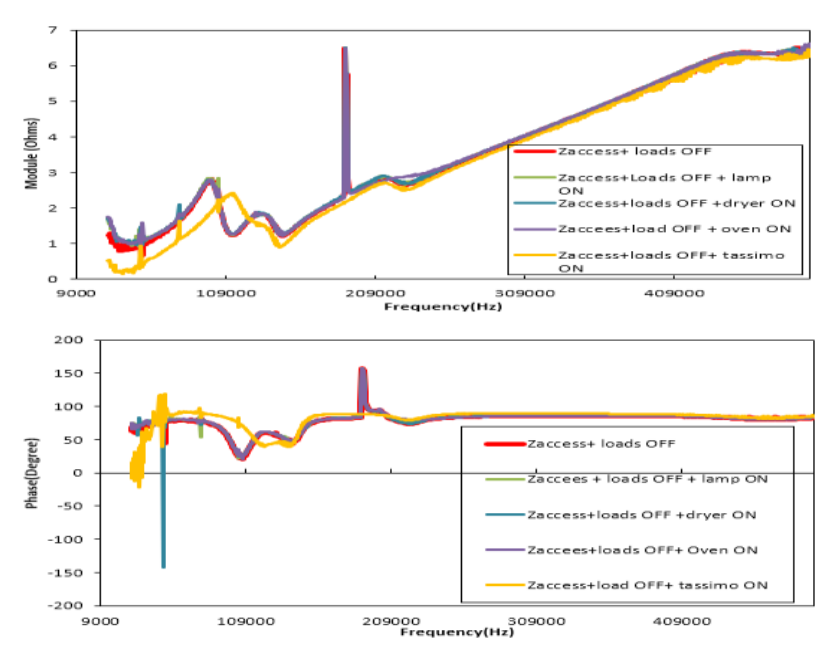

Fig. 16. Impact of some loads on the access impedance

The results show that the impact of the loads on the global impedance of the installation can be seen in the access impedance. The loads that have a high impedance are masked by low impedance loads.

\section{TIME VARIATION OF A DOMESTIC INSTALLATION IMPEDANCE}

The variation of Zinstallation. during 20 milliseconds is carried out in 201 frequencies between $30 \mathrm{kHz}$ to $500 \mathrm{kHz}$.

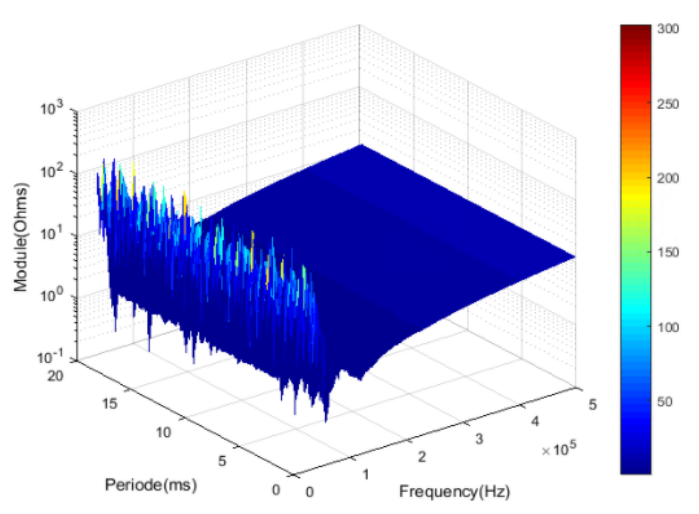

Fig. 17. Short-Time behavior of the installation impedance

The time varying behavior of a global impedance of installation show a low variation in the low frequencies. This time variation is the result of the time variation behavior of the domestic loads because the components of electrical devices depend on the instantaneous amplitude of the mains voltage $[7,8,11,12,13]$

\section{CONCLUSION}

This paper described a new measurement system of the global domestic installation in the frequency band between 30$500 \mathrm{kHz}$. An LCL filter is used to mask the impedance of the network. It has a high impedance representation and a short- time invariant behavior. The developed setup allows the measurement of the installation impedance without prior knowledge of the connected loads. A measurement campaign of the global impedance in several scenarios are used to study the frequency and the short-time variation of the installation impedance. The impact classification of the connecting of the loads and the operating mode changing are carried out following the realization of different scenarios. The paralleling of the measured global impedance and the network impedance allows the recalculation of the access impedance. The presented measurement results can be used to calculate the access impedance in any point of the network by the paralleling of the domestic installations impedances connected in the same branch.

\section{REFERENCES}

[1] K.Razazian,M.Umari,A.Kamalizad,V.Loginoc,M.Navid,"G3-PLC Specification for Powerline Communication: Overview, System Simulation and Field Trial Results" Power Line Communications and Its Applications (ISPLC) IEEE International Symposium ,June 2010.

[2] H.Bouassam ; M.Rifi ; V.Degardin, "Influence of load impedances on the quality of Power Line Communication", Electrical Sciences and Technologies in Maghreb (CISTEM), 2014 International Conference on

[3] Guangbin Chu, Jianqi Li, Weilin Liu,"Narrow Band Power Line Channel Characteristics for Low Voltage Access Network in China", ISPLC 2013

[4] G. Hooijen," Channel Model for the Residential Power Circuit Used as a Digital Communications Medium", IEEE TRANSACTIONS ON ELECTROMAGNETIC COMPATIBILITY, VOL. 40, NO. 4, NOVEMBER 1998

[5] Martin Sigle, Wenqing Liu, and Klaus Dostert," On the Impedance of the Low-Voltage Distribution Grid At Frequencies Up to $500 \mathrm{kHz}$, ISPLC 2012

[6] R.Nizigiyimana,J.C.Lebunetel,Y.Raingeaud,A.Achouri,"Characterizatio $\mathrm{n}$ and Modeling Breakers Effect on Power Line Communications", ISPLC2014

[7] G.Hallak,G.Bumiller," Impedance Measurement of Electrical Equipment Loads on the Power Line Network"," Power Line Communications and Its Applications (ISPLC) IEEE International Symposium 2017.

[8] M. Ait Ou Kharraz, C. Lavenu, P. Jensen, "Characterization of the Input Impedance of Household Appliances in the FCC Frequency Band", Power Line Communications and Its Applications (ISPLC) IEEE International Symposium 2017.

[9] M.Arzbergerl, K.Dostert, T.Waldeck, M.Zimmermann,” Fundamental Properties of the Low Voltage Power Distribution Grid",ISPLC1997

[10] Jorg Bausch, Timo Kistner, Marko Babic, Klaus Dostert," Characteristics of Indoor Power Line Channels in the Frequency Range 50-500 klz", Power Line Communications and Its Applications, 2006 IEEE International Symposium on

[11] Antoniali, Massimo, and Andrea M. Tonello. "Measurement and characterization of load impedances in home power line grids." IEEE Transactions

[12] Corripio, FJ Canete, et al. "Analysis of the cyclic short-term variation ofindoor power line channels." Selected Areas in Communications, IEEE Journal on 24.7 (2006): 1327-1338.

[13] Antoniali, Massimo, and Andrea M. Tonello. "Measurement and characterization of load impedances in home power line grids." IEEE Transactions on Instrumentation and Measurement 63.3 (2014): 548556.

[14] Adrian Z. Amanci, Francis P. Dawson, "Synchronization System with Zero-Crossing Peak Detection Algorithm for Power System Applications", The 2010 International Power Electronics Conferenc 